Article (refereed)

Cape, John Neil; van Dijk, Netty; Tang, Yuk Sim. 2009 Measurement of dry deposition to bulk precipitation collectors using a novel flushing sampler. Journal of Environmental Monitoring, 11. 353-358. doi:10.1039/B813812E

(C) The Royal Society of Chemistry 2009

This version available at http://nora.nerc.ac.uk/3787/

NERC has developed NORA to enable users to access research outputs wholly or partially funded by NERC. Copyright and other rights for material on this site are retained by the authors and/or other rights owners. Users should read the terms and conditions of use of this material at http://nora.nerc.ac.uk/policies.html\#access

This document is the author's final manuscript version of the journal article, incorporating any revisions agreed during the peer review process. Some differences between this and the publisher's version remain. You are advised to consult the publisher's version if you wish to cite from this article.

http://www.rsc.org/ 
Journal of Environmental Monitoring (2009), 11, 353-358: DOI: 10.1039/B813812E Published on web 31/10/08

\section{Measurement of dry deposition to bulk precipitation collectors using a novel flushing sampler.}

John Neil Cape, Netty van Dijk and Yuk Sim Tang

Centre for Ecology \& Hydrology, Bush Estate, Penicuik, Midlothian EH26 0QB, UK

\section{Summary}

Bulk precipitation samplers, which are continuously open, also sample gases and particles deposited on the funnel surface. Wet-only samplers, which open only during precipitation, avoid this problem, but can be bulky (leading to disruption of air flow and droplet collection) and need electrical power. We describe here a simple batterypowered modification to a standard bulk sampler that allows the separate measurement of deposition to the funnel surface and wet deposition by washing the funnel surface when precipitation is detected. Comparison of this design with a standard bulk sampler over 3 months at a site in eastern Scotland showed that dry deposition to the funnel surface contributed around $20 \%$ of sulphate, $20-30 \%$ of nitrate and $20-40 \%$ of ammonium ions. There was also a significant loss of ammonium and nitrate in the modified sampler, presumably in the tubing, even though a biocide had been added to the sample bottles. This observation has implications for bulk samplers of similar design, with a sample bottle at ground level. Deposition of sea salts and calcium was greater to the flushing collectors than to the bulk collectors, implying that regular cleaning of funnel surfaces with $10 \%$ methanol solution subtly alters the capture efficiency for larger particles.

\section{Introduction}

Measurements of the chemical composition of precipitation have been made for several decades using a variety of sampling methods. The simplest 'bulk' collector consists of a funnel (glass or plastic) connected to a sampling bottle, which may be changed daily, weekly or even monthly. This system is simple and does not require electrical power. However, the continuously-open sampling funnel is prone to 'contamination' by the dry deposition of gases and particles which are washed into the sample bottle and included in the precipitation sample. Consequently, several types of 'wet-only' collector have been devised, which are supplied with a lid which opens when precipitation is detected, and closes at the end of a precipitation event. Commercial designs may also included refrigeration of the samples to minimise losses caused by microbial activity. Such samplers require electrical power to operate the lid and cooling systems, and are often physically bulky compared to a simple funnel, leading to changes in air flow around the sampler and systematic undersampling of precipitation amount, particularly at high wind speeds, which may also bias the sample concentration. In any study of precipitation composition, the requirements, advantages and deficiencies of 'wet-only collectors have to be weighed against the low cost and ease of operation of bulk samplers, especially at remote sites where wet deposition may have detrimental effects on ecosystems.

The factors involved in effective operation of bulk samplers have been reviewed recently ${ }^{1}$, including a summary of comparisons between 'wet-only' samplers and bulk samplers. The review indicates that differences in flow distortion are likely to play the largest role in causing differences between bulk and wet-only collectors, and 
also identifies some properties of 'wet-only' samplers that may lead to unexpected bias in concentrations caused by retention and subsequent evaporation of water from the sampling funnel. Another recent review ${ }^{2}$ cites 9 studies where direct comparisons of 'wet-only' and bulk samplers have been made. In most cases, the deposition of material to the bulk collectors is significantly greater than to the 'wet-only' collectors, with the exception of free acidity $\left(\mathrm{H}^{+}\right)$and ammonium $\left(\mathrm{NH}_{4}^{+}\right)$which are often less in samples from bulk collectors than 'wet-only' collectors. In regional or national networks for precipitation chemistry, where cost or logistics prevent the widespread deployment of 'wet-only' samplers, bulk samplers have been used, accepting that there will be an uncertainty in the results caused by dry deposition to the collector surface. The magnitude of this uncertainty can be gauged to some extent by direct comparison of 'wet-only' and bulk collectors, but where bulk collectors have to be used, it would be helpful to be able to quantify the contribution of dry deposition to the actual bulk collector directly.

Several studies have attempted to quantify dry deposition by rinsing funnels on days without rain ${ }^{3}$, or by examining the process under controlled conditions using known air concentrations of potential contaminants ${ }^{4}$. However, neither approach captured the likely contribution to integrated bulk samples over typical sampling periods of a week or more. This study describes the design and implementation of a novel 'flushing' sampler that separately collects funnel washings and 'clean' rain for subsequent chemical analysis and quantification.

\section{Design}

Conventional 'wet-only' collectors use a lid to prevent dry deposition to the funnel surface between rain events. Some designs use a 'dry bucket' which is covered during rainfall, then rinsed and analysed to estimate dry deposition between rain events. However, the surfaces of the 'dry bucket' are not exposed to wetting, and therefore may saturate (in terms of surface adsorption), and will have very different characteristics from the surface of a bulk collector which is intermittently wetted by rain. In order to make a direct comparison with the standard bulk collector used in the UK 'Acid deposition' network ${ }^{5}$, a standard collector with a low density polyethylene (LDPE) funnel diameter $152 \mathrm{~mm}$ leading directly to a high density polyethylene (HDPE) sample bottle, at $1.5 \mathrm{~m}$ above ground (Just Plastics Ltd, UK) has been modified to include a mechanism which rinses the funnel surface when rain is detected. A sketch of the design is shown in Figure 1; rainfall is detected using a conventional unheated surface wetness sensor (Campbell Scientific) mounted at $45^{\circ}$ to the vertical. When rain is detected, a solution of $10 \%$ methanol in deionised water is pumped from a storage reservoir using a $12 \mathrm{~V} \mathrm{DC}$ pump (similar to a car windscreen washer pump) through a spray nozzle mounted on stainless steel rods immediately above the centre of the funnel. A spray duration of 5 seconds (ca. $20 \mathrm{ml}$ ) is adequate to wet the funnel surface. The funnel washings are directed through a motorised PTFE 3-way valve to a sample bottle at the foot of the collector through silicone rubber tubing enclosed in an opaque flexible hose to exclude light. After 50 seconds the valve rotates so that subsequent rainfall is directed to a second sample bottle for the duration of the rain event. Once the surface wetness sensor dries, the valve returns to the original sampling position. A delay time of 120 minutes is built into the mechanism so that the valve remains open for rainfall collection during intermittent 
Journal of Environmental Monitoring (2009), 11, 353-358: DOI: 10.1039/B813812E Published on web 31/10/08

rainfall. The instrument operates on $12 \mathrm{~V}$ DC from a lead-acid battery and so may be operated at sites remote from mains electrical power.

Figure 1 near here

Methanol is added to the spray solution to reduce surface tension (improve wetting) and inhibit microbial activity. Both sample bottles (for 'washings' and 'rain') are preloaded with thymol (5-methyl-2-(1-methylethyl)phenol) to provide a minimum solution concentration of $50 \mathrm{mg}$ litre $^{-1}$ for a full bottle, sufficient to prevent biological degradation of labile nitrogen compounds during sampling ${ }^{6,7}$. For this study samples were taken every 7 days, for direct comparison with the standard UK bulk rainfall collector, to which was added a 'dummy' spray head so that any differential capture of fine droplets would be similar for both designs (see Figure 1). Six collectors (3 standard UK bulk collectors with dummy spray heads, and 3 flushing collectors) were set out in a gravelled area $5 \mathrm{~m} \times 7 \mathrm{~m}$ in a grass field within the grounds of CEH Edinburgh, in south-east Scotland (Lat 55:51:44N, Long 3:12:20W). After several months of method development and testing of the sampler design, direct comparison of the bulk and flushing collectors started on 15 June 2006 and continued until 5 October 2006. A recording tipping bucket rain gauge was also installed at the site, to provide information on when rainfall occurred, and the duration of individual rain events, where an 'event' is defined as a period during which the tipping bucket rain gauge gave non-zero readings in consecutive hours.

Sample volumes were measured gravimetrically each week, and concentrations of major ions (excluding $\mathrm{H}^{+}$) were measured using ion chromatography (Metrohm). Detection limits for the individual ions were typically $2 \mu \mathrm{M}$ or less. Samples of the flushing solution ( $10 \%$ methanol in water) were also analysed - the only ion concentrations measured that were above the detection limits were for $\mathrm{Ca}^{2+}$ (average $3.5 \mu \mathrm{M}$ ), and 'washings' data have been corrected for this contribution from the washing solution. Data from samples with obvious contamination (e.g. from birds) or from samples with high $\mathrm{NH}_{4}{ }^{+}$and $\mathrm{K}^{+}$concentrations (also indicative of bird contamination) were discarded. If only one sample from a triplicate set was contaminated, data were estimated from the average of the other 2 samples. During the sampling period of 16 weeks, 4 weeks had insufficient rainfall for a sample, and in one week almost all samplers were contaminated, leaving a total of 11 weekly samples for statistical analysis. In weeks with insufficient rainfall, collectors were cleaned as usual, and sampling bottles were replaced.

In order to estimate the relative contribution to deposition in the washings and in the rain, the total amount of material deposited in each sample was calculated from the product of the volume and concentration, to give deposition as micromoles $\mathrm{m}^{-2} \mathrm{wk}^{-1}$. Measured air concentrations of trace gases and particles close to the sampling site were extracted from the database of the UK Nitric Acid monitoring network, which is operated by CEH (http://www.cara.ceh.ac.uk/hno3network/index.html).

\section{Statistical analysis}

Data are presented in the following tables and figures as the weekly mean deposition, with variability expressed as the standard deviation of data from the 3 independent collectors of each type. In theory, the sum of the deposition in the washings and the 
Journal of Environmental Monitoring (2009), 11, 353-358: DOI: 10.1039/B813812E Published on web 31/10/08

rain should equal the deposition to the bulk collector. In order to test this, data were analysed by two-way analysis of variance, using sample date and collector type as variates, with triplicate data from the independent collectors.

\section{Results}

\section{Water}

There was a small (4\%) but statistically significant difference between the amounts of water collected by the bulk collector and the flushing collector (Table 1), with the smaller volumes from the flushing collector. This finding confirmed data obtained during the development of the equipment, when the 6 collectors ( 3 bulk, 3 flushing) were exposed between March and May 2006 without the mechanism in operation i.e. with the valve fixed in one position. Under these conditions, the average weekly volume collected in the bulk collectors was $266 \pm 8 \mathrm{ml}$, compared with $254 \pm 2 \mathrm{ml}$ in the continuously open flushing collectors (each with 3 collectors, 7 weekly samples), a difference of $5 \%$. The difference between the two sets of collectors, which have similar geometry and therefore should have caused the same flow distortion, may result from some trapping of water in the valve (mounted immediately below the funnel, Figure 1) in the flushing collector at the end of each rain event, and the subsequent evaporation of small volumes of water. The volume involved is small, equivalent to $1.5 \mathrm{ml}$ per rain event. There was no evidence of water leakage from the continuously open flushing collectors. Consequently, the smaller volumes observed from the flushing collector relative to the bulk collector between June and October 2006 are most likely caused by the same mechanism, rather than because some of the rain was sampled into the 'washings' sample bottle before the valve operated.

\section{Sea-salts}

Sodium, chloride and magnesium data show a small but significantly greater overall deposition (washings + rain) to the flushing collector than to the bulk collector (Table 1 ), despite the smaller volume of water collected as rain by the flushing collector. More importantly, the data show that approximately one-third of the sea-salt deposition measured in the bulk collector was contributed from dry-deposited material on the funnel surface, recovered as the funnel washings in the flushing collector.

\section{Calcium and potassium}

There was a large (50\%) excess deposition of calcium to the flushing collectors compared to the bulk collectors (Table 1), and half of this was observed in the 'rain' component, suggesting that the 5 second flushing with the $10 \%$ methanol/water solution was not completely effective in removing surface-deposited material. Consequently, the overall contribution of dry deposition from washings of between 20 and $30 \%$ of the total (Table 1) is probably an underestimate. Potassium data were often close to the limit of detection and showed large variation across samplers, so that no significant difference was observed between sampler types.

\section{Sulphate}

There was no significant difference in the deposition of sulphate, either as total sulphate or non-sea sulphate (estimated using the sodium:sulphate ratio in sea water), between the bulk and flushing collectors. However, the contribution of dry deposition estimated from the funnel washings (Table 1) was around $20 \%$ of the total. Part of this may have arisen from sulphate particles and part from gaseous sulphur dioxide. 
Average air concentrations over the 3 months July-September 2006 measured approximately $200 \mathrm{~m}$ from the sampling site (http://www.cara.ceh.ac.uk/hno3network/ index.html) were $1.0 \mu \mathrm{g} \mathrm{SO}_{4}{ }^{2-} \mathrm{m}^{-3}$ and $0.97 \mu \mathrm{g} \mathrm{SO}_{2} \mathrm{~m}^{-3}$. The estimated dry deposition of non-sea sulphate of $0.09 \mathrm{mmole} \mathrm{m}^{-2} \mathrm{wk}^{-1}$ (Table 1) therefore corresponds to a deposition velocity to the collector of $0.01 \mathrm{~m} \mathrm{~s}^{-1}$ if all from $\mathrm{SO}_{2}$, or $0.015 \mathrm{~m} \mathrm{~s}^{-1}$ if all from particulate $\mathrm{SO}_{4}{ }^{2-}$.

\section{Nitrate}

The most notable feature of the nitrate data is the overall large loss of nitrate in the flushing collector (washing + rain) compared with the bulk collector (Table 1). As a biocide was added to the sample bottles prior to deployment, the losses must have occurred in the $1.5 \mathrm{~m}$ lengths of silicone rubber tubing leading from the valve to the storage bottles, even though the tubing and bottles were kept in the dark. The standard sample funnel leads directly into the sample bottle, so collected precipitation would have been protected immediately by the biocide. Nevertheless, a significant fraction (20-30\%, Table 1) of the nitrate sampled was in the washings, suggesting that dry deposition on the surface of the bulk collector constitutes a large proportion of the measured nitrate deposition. Gaseous nitric acid and particulate nitrate concentrations over the 3 months were $0.9 \mu \mathrm{g} \mathrm{HNO}_{3} \mathrm{~m}^{-3}$ and $1.2 \mu \mathrm{g} \mathrm{NO}_{3}{ }^{-} \mathrm{m}^{-3}$. The measured deposition in washings of $0.15 \mathrm{mmole} \mathrm{m}^{-2} \mathrm{wk}^{-1}$ (Table 1) represents a lower bound (given the loss of total nitrate) to the dry deposition, and corresponds to a deposition velocity to the collector of $0.018 \mathrm{~m} \mathrm{~s}^{-1}$ if all from $\mathrm{HNO}_{3}$, or $0.013 \mathrm{~m} \mathrm{~s}^{-1}$ if all from particulate $\mathrm{NO}_{3}{ }^{-}$.

\section{Ammonium}

As for nitrate, almost half of the ammonium measured in the bulk collectors was lost from the washings + rain measured in the flushing collectors, again presumably through biological activity in the sample tubing. However, the washings contributed up to $40 \%$ of the sampled ammonium, indicating a significant contribution from dry deposition, of at least $0.21 \mathrm{mmole} \mathrm{m}^{-2} \mathrm{wk}^{-1}$ (Table 1). Gaseous ammonia and particulate ammonium concentrations over the 3 months were $1.8 \mu \mathrm{g} \mathrm{NH}_{3} \mathrm{~m}^{-3}$ and 0.9 $\mu \mathrm{g} \mathrm{NH}_{4}{ }^{+} \mathrm{m}^{-3}$. The measured deposition in washings represents a lower bound (given the loss of total ammonium) to the dry deposition, and corresponds to a deposition velocity to the collector of $0.003 \mathrm{~m} \mathrm{~s}^{-1}$ if all from $\mathrm{NH}_{3}$, or $0.007 \mathrm{~m} \mathrm{~s}^{-1}$ if all from particulate $\mathrm{NH}_{4}^{+}$.

Table 1 near here

\section{Discussion}

There have been many studies comparing adjacent bulk and wet-only precipitation collectors, in many parts of the world. Most of the key research up to 2003 was summarized recently ${ }^{2}$, and subsequent studies ${ }^{8-11}$ come to similar conclusions:

1. the difference between bulk and wet-only samplers is very dependent on location (rural, suburban, urban) ${ }^{12}$ and surrounding terrain (arid, grassland) ${ }^{2}$;

2. soil-derived ions from large wind-blown particles such as $\mathrm{Ca}^{2+}, \mathrm{Mg}^{2+}, \mathrm{K}^{+}$and sometimes $\mathrm{SO}_{4}{ }^{2-}$, or sea-salt ions $\left(\mathrm{Na}^{+}, \mathrm{Cl}^{-}\right)$show much larger enhancements than for ions derived from gases or sub-micron particles $\left(\mathrm{NH}_{4}^{+}, \mathrm{NO}_{3}{ }^{-}, \mathrm{SO}_{4}{ }^{2-}\right)$;

3. longer sampling periods (e.g. week vs. day) show greater enhancements ${ }^{10,11,13}$; 
4. sampler design is an important factor controlling the chemical composition of the precipitation sample i.e. different designs give different results ${ }^{10,14}$;

5. there can be large spatial variability over a small area if replicate samplers are deployed (which is not often the case) ${ }^{14}$.

This study is unique in several respects. Firstly, the novel design of the 'flushing' gauge permits a more accurate assessment of the contribution of dry deposition to the collector surface of a bulk collector than the use of an adjacent 'dry bucket' as used in some designs ${ }^{15}$. The physical and chemical characteristics of the flushing gauge were identical in respect of the collecting surface; only the subsequent tubing and sample storage was different. Moreover, a biocide was used to minimise biological degradation in the stored sample, as has been used in some comparison studies ${ }^{11}$, but is not usual. Secondly, the use of multiple replicates of both types of collector within a small area has permitted an assessment to be made of the spatial and temporal uncertainties arising from the use of such collectors, which in general are not adequately represented, with experiments comparing only one example of each type of 'co-located' collector.

The results confirmed the general pattern of the greater enhancements in bulk deposition of ions associated with large particles $\left(\mathrm{Ca}^{2+}\right.$ and sea salts), and small differences for $\mathrm{SO}_{4}{ }^{2-}$. The complication arising from loss of $\mathrm{N}$-containing ions in the flushing sampler precluded a direct comparison of the two types of collector, but it is notable that in some studies the deposition of $\mathrm{NH}_{4}{ }^{+}$to bulk samplers is reported as less than to wet-only samplers ${ }^{2}$. It is possible that in these cases any dry-deposited $\mathrm{NH}_{3}$ or $\mathrm{NH}_{4}{ }^{+}$was more susceptible to biological degradation in a continuously-open sampler than in a lidded wet-only sampler, and therefore showed lower collected amounts even though actual deposition may have been higher to the bulk sampler.

Dry deposition to the surface of the UK standard bulk precipitation collector at this site over 3 months contributed a significant proportion of the input of material recorded in solution, varying between $20 \%$ (for sulphate) and $40 \%$ (for ammonium). There is some uncertainty in the proportion of nitrogen-containing ions that are deposited through dry deposition, because of losses in the flushing sampler, but the amounts recovered from the washings clearly indicate a substantial contribution of dry deposition to the total.

Previous attempts at quantifying dry deposition to bulk collectors at this site relied on laboratory experiments or manual rinsing of funnels on days without rainfall. The early studies using manual funnel washings ${ }^{3}$ suggested a contribution to sulphate from dry deposition of $22 \%$, similar to the proportion observed in this study, despite the difference in time (1977 vs. 2006), funnel surface (Pyrex glass vs. HDPE), and air concentrations at the site $\left(5.7 \mu \mathrm{g} \mathrm{SO}_{4}{ }^{2-} \mathrm{m}^{-3}\right.$ and $23 \mu \mathrm{g} \mathrm{SO}_{2} \mathrm{~m}^{-3}$ in 1977, compared with $1.0 \mu \mathrm{g} \mathrm{SO}_{4}{ }^{2-} \mathrm{m}^{-3}$ and $0.97 \mu \mathrm{g} \mathrm{SO}_{2} \mathrm{~m}^{-3}$ in 2006). The later process-based studies ${ }^{4}$ using controlled exposure of UK standard bulk collector funnels (HDPE) to $\mathrm{SO}_{2}$ and $\mathrm{NH}_{3}$ indicated a contribution from dry deposition of $\mathrm{SO}_{2}$ to dry funnels of 85-120 nmole funnel ${ }^{-1} \mathrm{~d}^{-1}$, equivalent to 0.03 to $0.05 \mathrm{mmole}^{-2} \mathrm{wk}^{-1}$ (cf. average washing of 0.09 mmole $\mathrm{m}^{-2} \mathrm{wk}^{-1}$, Table 1). That study also showed dry deposition of $\mathrm{NH}_{3}$ to dry funnels between 70 and 120 nmole funnel ${ }^{-1} \mathrm{~d}^{-1}\left(0.03\right.$ to $\left.0.05 \mathrm{mmole} \mathrm{m}^{-2} \mathrm{wk}^{-1}\right)$, with deposition to wet funnels a factor of 5 greater, compared with the average deposition measured in washings in this study of $0.21 \mathrm{mmole} \mathrm{m}^{-2} \mathrm{wk}^{-1}$ (Table 1). 
The assumption made above is that the washings may be directly related to material dry-deposited on funnel surfaces between rain events. However, there may also be some contribution from the early part of rainfall, during the first minute after rainfall is detected and before the valve changes position. Sequential sampling of rainfall composition often shows a high initial concentration ${ }^{16,17}$, although ensuring a clean sampler at the exact start of a rain event is practically very difficult to achieve. However, a similar problem would be seen for conventional wet-only samplers, where the initial rainfall that triggers opening of the lid may not actually be captured ${ }^{14}$. There was no evidence from comparing water sampling rates that a significant fraction of water was diverted to the washings at the start of a rain event, rather than to the rain sample bottle.

As noted above, the consistently lower sampling (by 4-5\%) of water by the flushing gauge may be caused by retention and subsequent evaporation of rain in the valve assembly. Any soluble material (at most $4-5 \%$ ) retained in the valve at the end of each rain event would be flushed into the washings at the start of the next event and be recorded as 'dry deposition'. Consequently there may be a systematic positive bias in estimated dry deposition of up to $5 \%$ of the total deposited. Set against this, we have assumed that the 5-second washing process completely removes all dry-deposited material from the funnel surface. In practice the evidence suggests that for calcium, at least, the process is not completely efficient, leading to a potential negative bias in the measurements.

The data for ammonium and nitrate highlight the difficulties of studying labile species even when precautions have been taken to prevent biological activity during sampling. Further measurements have been made and will be reported in a subsequent paper. However, the message is clear, even if the size of the bias is not well defined (24-44\% for ammonium, $17-30 \%$ for nitrate). There are also implications for measurement systems where collector funnels are mounted at $1.5 \mathrm{~m}$ and connected to sampling bottles at ground level by tubing ${ }^{1}$, even when the bottles are kept in the dark and refrigerated or protected using a biocide. It is not clear whether different tubing materials (e.g. PTFE) would lead to smaller losses of labile compounds.

The reason for the greater deposition rates of particles (sea-salts, calcium) to the flushing collector than to the bulk collector is not immediately apparent. In principle, the geometry and materials of both types of collector are identical. The only difference is that the funnel surfaces of the flushing gauge are regularly washed with $10 \%$ methanol/water solution, which may change the pattern of surface wetting and the capacity of the funnel surface to retain wind-borne particles.

\section{Conclusions}

The development of a novel design of precipitation collector has permitted the estimation of dry deposition to a standard bulk collector as used in the UK national precipitation network. The results indicate significant positive bias in reporting bulk rainfall composition relative to the likely actual composition of rainfall, at least over a 3 -month period at one site. The data are also consistent with earlier measurements of dry deposition to bulk rainfall collectors at this site in eastern Scotland. 
Journal of Environmental Monitoring (2009), 11, 353-358: DOI: 10.1039/B813812E Published on web 31/10/08

The implications of these results for the UK bulk precipitation monitoring network are important: it would appear that wet deposition of S and $\mathrm{N}$ to the UK is being overestimated by an undefined amount, but possibly of the order of 20 to $40 \%$. The extent of the dry deposition to the collectors will vary spatially, depending on the air concentrations of the contributory gases and particles. However, as discussed in the earlier paper ${ }^{4}$, the average deposition velocities calculated above for this site over 3 months are unlikely to be directly applicable to other sites and times of year, because of the variation of dry deposition rates with surface wetting. For a full assessment of the likely bias across the UK it would be necessary to install similar collectors at all the UK network sites.

\section{Acknowledgements}

The authors acknowledge financial support from the UK Department of the Environment, Food and Rural Affairs (Defra) under contract RMP2258, and the help of David Benham (CEH Lancaster) in designing the circuitry and building the flushing rain collectors.

\section{References}

1. U. Dämmgen, J. W. Erisman, J. N. Cape, L. Grünhage and D. Fowler, Environmental Pollution, 2005, 134, 535-548.

2. J. Staelens, A. De Schrijver, P. Van Avermaet, G. Genouw and N. Verhoest, Atmospheric Environment, 2005, 39, 7-15.

3. D. Fowler and J. N. Cape, Atmospheric Environment, 1984, 18, 183-189.

4. J. N. Cape and I. D. Leith, Atmospheric Environment, 2002, 36, 5983-5992.

5. H. Lawrence, K. Vincent, M. Smith, C. Colbeck, Y. S. Tang, M. A. Sutton, I. Simmons, L. Love, E. Vogt, N. Van Dijk, J. N. Cape and R. I. Smith, UK Acid Deposition Monitoring Network: Data Summary 2006, AEA Technology, Harwell, 2007.

6. D. A. Hadi and J. N. Cape, International Journal of Environmental Analytical Chemistry, 1995, 61, 103-116.

7. J. N. Cape, A. Kirika, A. P. Rowland, D. R. Wilson, T. D. Jickells and S. Cornell, The Scientific World, 2001, 1, 230-237.

8. A. F. Pelicho, L. D. Martins, S. N. Nomi and M. C. Solci, Atmospheric Environment, 2006, 40, 6827-6835.

9. B. O. Akkoyunlu and M. Tayanc, Atmospheric Environment, 2003, 37, 3571-3579.

10. R. Balestrini, S. Arisci, M. C. Brizzio, R. Mosello, M. Rogora and A. Tagliaferri, Atmospheric Environment, 2007, 41, 745-756.

11. S. Chantara and N. Chunsuk, Atmospheric Environment, 2008, 42, 5511-5518.

12. J. R. Stedman, C. J. Heyes and J. G. Irwin, Water Air and Soil Pollution, 1990, 52, 377-395.

13. P. A. Tanner, Atmospheric Environment, 1999, 33, 1757-1766.

14. J. W. Erisman, H. Möls, P. Fonteijn, M. Geusebroek, G. Draaijers, A. Bleeker and D. van der Veen, Environmental Pollution, 2003, 125, 139-155.

15. J. M. Dasch and S. H. Cadle, Atmospheric Environment, 1985, 19, 789-796.

16. K. Hansen, G. P. J. Draaijers, W. P. M. F. Ivens, P. Gundersen and N. F. M. Vanleeuwen, Atmospheric Environment, 1994, 28, 3195-3205.

17. W. Q. Luo, Atmospheric Environment, 2001, 35, 6219-6225. 
Table 1: Deposition to standard bulk rain collectors and 'flushing' collectors between 15 June and 5 October 2006. Results are given as mmole $\mathrm{m}^{-2} \mathrm{wk}^{-1}$ for each ion, and $\mathrm{mm}$ for rain, averaged over 11 weekly samples. Standard errors of data from 3 replicate collectors are shown.

\begin{tabular}{|c|c|c|c|c|c|c|c|c|c|c|}
\hline & rain $(m m)$ & sodium & ammonium & potassium & calcium & magnesium & chloride & nitrate & sulphate & $\begin{array}{l}\text { non-sea } \\
\text { sulphate }\end{array}$ \\
\hline Standard & 34.9 & 0.76 & 0.87 & 0.11 & 0.30 & 0.15 & 0.99 & 0.89 & 0.48 & 0.44 \\
\hline std dev of 3 samplers & 0.3 & 0.06 & 0.07 & 0.06 & 0.02 & 0.01 & 0.06 & 0.02 & 0.02 & 0.02 \\
\hline Rain & 33.3 & 0.56 & 0.26 & 0.05 & 0.37 & 0.13 & 0.85 & 0.36 & 0.34 & 0.31 \\
\hline std dev of 3 samplers & 1.1 & 0.13 & 0.04 & 0.03 & 0.03 & 0.02 & 0.14 & 0.09 & 0.02 & 0.02 \\
\hline Wash & 25.5 & 0.27 & 0.21 & 0.04 & 0.09 & 0.06 & 0.34 & 0.15 & 0.11 & 0.09 \\
\hline std dev of 3 samplers & 2.6 & 0.09 & 0.04 & 0.02 & 0.02 & 0.01 & 0.12 & 0.02 & 0.01 & 0.01 \\
\hline Rain + Wash & & 0.83 & 0.47 & 0.09 & 0.45 & 0.19 & 1.19 & 0.52 & 0.45 & 0.40 \\
\hline std dev of 3 samplers & & 0.05 & 0.03 & 0.04 & 0.02 & 0.02 & 0.16 & 0.11 & 0.03 & 0.02 \\
\hline Dry deposition (\%) & & sodium & ammonium & potassium & calcium & magnesium & chloride & nitrate & sulphate & $\begin{array}{l}\text { non-sea } \\
\text { sulphate }\end{array}$ \\
\hline $\begin{array}{l}\text { Washing as } \\
\% \text { standard gauge }\end{array}$ & & $36 \%$ & $24 \%$ & $41 \%$ & $29 \%$ & $39 \%$ & $35 \%$ & $17 \%$ & $23 \%$ & $21 \%$ \\
\hline $\begin{array}{l}\text { Washing as } \\
\% \text { (rain+wash) }\end{array}$ & & $32 \%$ & $44 \%$ & $46 \%$ & $19 \%$ & $32 \%$ & $29 \%$ & $30 \%$ & $24 \%$ & $23 \%$ \\
\hline $\begin{array}{l}\text { Comparison of totals } \\
\text { from flushing and } \\
\text { standard collectors }\end{array}$ & rain & sodium & ammonium & potassium & calcium & magnesium & chloride & nitrate & sulphate & $\begin{array}{l}\text { non-sea } \\
\text { sulphate }\end{array}$ \\
\hline $\begin{array}{l}\text { Average \% (rain+wash)/ } \\
\text { standard } \\
\text { ANOVA (rain + wash) }\end{array}$ & $96 \%$ & $110 \%$ & $54 \%$ & $89 \%$ & $150 \%$ & $122 \%$ & $120 \%$ & $58 \%$ & $93 \%$ & $91 \%$ \\
\hline $\begin{array}{l}\text { vs. Standard } \\
\text { (Probability that both } \\
\text { are same) }\end{array}$ & $0.0001^{* * *}$ & $0.044^{*}$ & $0.000^{* * *}$ & 0.786 & $0.000^{* * *}$ & $0.000^{* * *}$ & $0.0007^{* * *}$ & $0.000^{* * *}$ & 0.156 & 0.110 \\
\hline
\end{tabular}




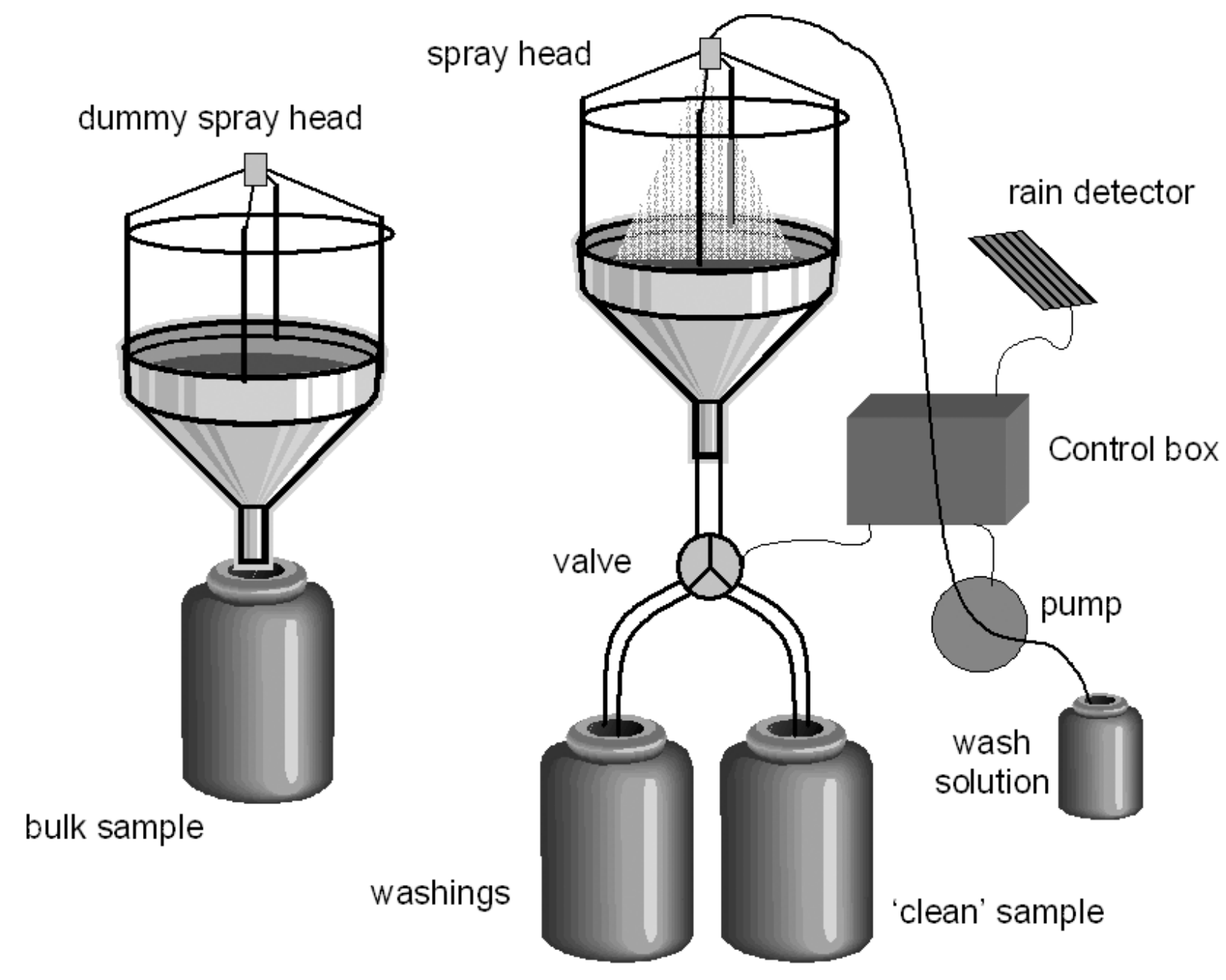

Figure 1. Schematic diagram of flushing collector (right) and modified standard collector (left) showing dummy spray head. 
Journal of Environmental Monitoring (2009): DOI: 10.1039/B813812E

Published on web 31/10/08

\section{Graphical contents entry}

Flushing rain collector measures dry deposition to bulk rain gauges

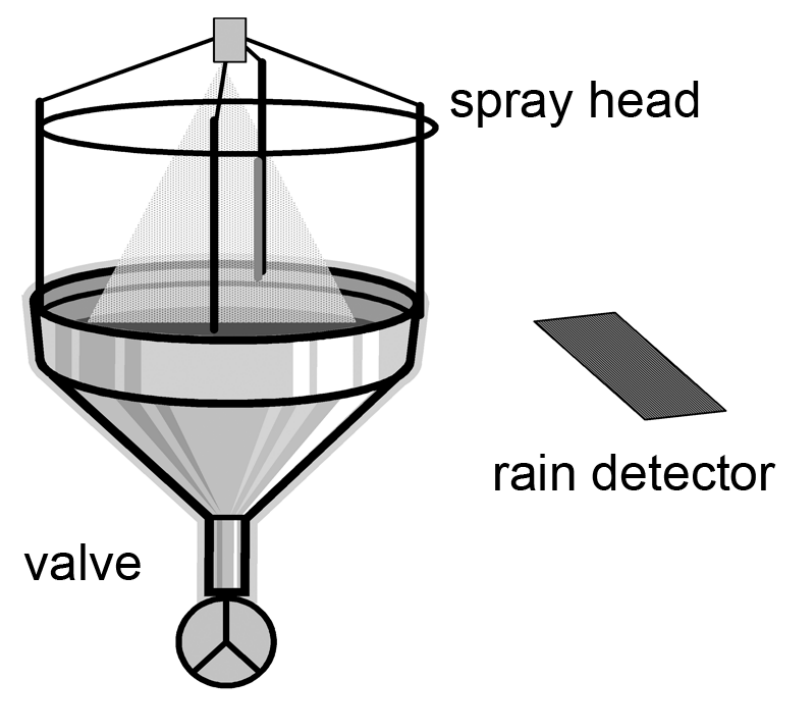

